\title{
Delayed massive immune hemolysis mediated by minor ABO incompatibility after allogeneic peripheral blood progenitor cell transplantation
}

\author{
J.-P. Salmon, S. Michaux, J.-P. Hermanne, E. Baudoux, \\ C. Gérard, D. Sontag-Thull, G. Fillet, and Y. Beguin
}

BACKGROUND: Bone marrow transplantation with minor ABO incompatibility may be followed by moderate delayed hemolysis of the recipient's red cells by donorderived ABO antibodies. This reaction may be more severe after transplantation of peripheral blood progenitor cells (PBPCs).

CASE REPORT: A 16-year-old boy underwent an allogeneic PBPC transplant from his HLA-mismatched mother as treatment for acute myeloblastic leukemia that had proved resistant to induction chemotherapy. Transfusion of the unmanipulated PBPCs proceeded without any complication, despite the difference in $\mathrm{ABO}$ blood group (donor, O Rh-positive; recipient, A Rh-positive). On Day 7, a rapid drop in hemoglobin to $4 \mathrm{~g}$ per $\mathrm{dL}$ was observed, which was attributed to a massive hemolysis. All the recipient's group A red cells were destroyed within 36 hours. This delayed and rapidly progressive hemolytic anemia was not associated with the transfusion of the donor's plasma. Rather, the anti-A titer increased in parallel with marrow recovery, which suggested an active synthesis of these antibodies by immunocompetent cells from the donor against the recipient's red cells. The mother's anti-A titer was retrospectively found to be 2048 . Her unusually high titer is probably due to prior sensitization during pregnancies. On Day 12 , the patient developed grade IV graft-versus-host disease, which proved resistant to all treatments instituted and led to his death on Day 35.

CONCLUSION: PBPC transplantation with minor $\mathrm{ABO}$ incompatibility may be associated with significant risk of massive delayed hemolysis.
$\mathrm{B}$

one marrow transplantation can be carried out successfully between donorsand recipients who have ABO incompatibilities, provided that measures are taken to avoid acute hemolytic reactions after thetransfusion of incompatible red cells (RBCs)., ${ }^{1,2}$ There are two types of ABO incompatibility. One type, referred to as minor, may involve hemolysis after the destruction of a proportion of the patient's RBCs by the anti-A or anti-B present in thesmall quantity of plasma contained in the graft. The other type, referred to as major, involves the systemic presence in the recipient of $A B O$ antibodies against the RBC antigens of the donor. Theseantibodies will mediate severe acute hemolytic reactions if the incompatible RBCs are not removed from the graft.

We present a case of massive delayed hemolysis of the recipient's RBCs by donor-derived $A B O$ antibodies after peripheral blood progenitor cell (PBPC) transplant with minor ABO incompatibility. This hemolysis was probably due to recall immunity in relation to previous pregnancies of the donor, in the context of an extremely precocious recovery of donor-derived whitecells, which is a result of the very rapid hematopoietic engraftment associated with PBPCs and the use of granulocyte-colony-stimulating factor (G-CSF).
ABBREVIATIONS: ara-C = arabinoside-cytosine; G-CSF = granulocyte-colony-stimulating factor; GVHD = graft-versushost disease; $\mathrm{PBPC}(\mathrm{s})=$ peripheral blood progenitor cell(s); $\mathrm{RBC}(\mathrm{s})=$ red cell(s).

From the Division of Hematology, Department of Medicine, Blood Transfusion Center, University of Liège, Liège, Belgium.

Address reprint requests to: Yves Beguin, MD, Department of Hematology, CHU Sart Tilman, University of Liège, 4000 Liège, Belgium; e-mail: yves.beguin@chu.ulg.ac.be.

Yves Beguin is Senior Research Associate of the National Fund for Scientific Research (FNRS, Belgium).

Received for publication October 1, 1998; revision received and accepted January 11, 1999.

TRANSFUSION 1999;39:824-827. 


\section{CASE REPORT}

A 16-year-old boy was diagnosed with acute myeloblastic leukemia M 1 according to the FAB classification, with trisomy 8 , in the context of back pain as well as multiple febrile episodes that were resistant to antibiotics. Hehad no other particular antecedent medical problem. He underwent a first course of induction chemotherapy with mitoxantrone, arabinoside-cytosine (ara-C), and etoposide, which resulted in failure, with persistence of 16-percent blast cells in the bone marrow. A second line of treatment based on amsacrineand intermediate-doseara- $C$ was then administered, but the patient again did not reach a complete remission. In light of this refractory leukemia, an allogeneic transplant was proposed as the therapeutic solution of last resort, in full awareness that it represented only a 10-percent chance of cure. The preparative regimen consisted of ara-C, cyclophosphamide, and an 8-Gy singledose of total body irradiation, with intrathecal administration of methotrexate. Infection prophylaxis was based on trimethoprim/cotrimoxazole, ciprofloxacin, fluconazole, and ganciclovir before transplant, followed by acyclovir after transplant, as well as polyvalent immunoglobulins. Graft-versus-host disease(GVHD) prophylaxis consisted of cyclosporine A alone.

The donor was the patient's mother, who had a major HLA mismatch at the D locus, as well as a different $A B O$ group (donor, O Rh-positive; recipient, A Rh-positive). It should be noted that she had undergonefour pregnancies and had received one RBC transfusion. To carry out the transplant, the donor's marrow wasstimulated with G-CSF (10 $\mu \mathrm{g} / \mathrm{kg})$ for 5 days and PBPCs were collected by cytapheresis on 2 consecutive days. Erythropoietin, $600 \mathrm{U}$ per kg twice a week, was also given for 3 weeks before and 3 weeks after the transplant, to proceed in parallel with the collection of autologous RBC concentrates for use in the recipient as needed. The return of the unmanipulated PBPCs (12.23 × $10^{6} \mathrm{CD} 34+$ cells/ $\left.\mathrm{kg}\right)$ proceeded without complication, and, in particular, no acute hemolytic reaction was engendered on Day 0 or Day 1 . From that timeon, the patient received only filtered and irradiated O Rh-positive RBC concentrates (these being by priority those taken from the donor), as well as group O Rh-positive single-donor platelet concentrates resuspended in group A plasma.

The patient was provided with $5 \mu \mathrm{g}$ per $\mathrm{kg}$ of G-CSF from Day 1 through Day 12 and with $200 \mathrm{U}$ per kg of erythropoietin from Day 1 through Day 33. Neutrophil recovery was prompt, with $0.5 \times 10^{9}$ polymorphonuclear neutrophils per $L$ achieved on Day 9 and $2 \times 10^{9}$ on Day 10 . The platelets never attained a value of $20 \times 10^{9}$ per $\mathrm{L}$, as their recovery was hampered by the severe gastrointestinal bleeding observed later. As for the RBC lineage, early signs of recovery were noted by Day 10, with a reticulocyte count of 1 percent, which attained a maximum value of 14 percent on Day 20 before returning to aplastic values thereafter. How- ever, the patient never becameindependent of transfusion, first because of hemolysis and then because of the gastrointestinal bleeding (see below).

The posttransplant course was first complicated by Staphylococcusepidermi disbacteremia on Day3. Then, the hemoglobin dropped dramatically from $8.5 \mathrm{~g}$ per dL on Day 6 to $4 \mathrm{~g}$ per dL on Day 8, without any evidence of bleeding (Fig. 1). The drop in hemoglobin occurred concomitantly with hematopoietic recovery, which wasalso accompanied by a major increase in serum bilirubin $(556 \mu \mathrm{mol} / \mathrm{L}$ on Day 8) and lactate dehydrogenase (1218IU/L on Day 9), a complete disappearance of haptoglobin, and a positive direct antiglobulin test. Renal function was maintained. The group A RBCs from the recipient were accordingly destroyed within 36 hours. Therecipient was group A until Day 6 , showed a mixed-field population with very few group $A$ RBCsamong group O cells on Day 7 , and was group $O$ from Day 8 on (Table 1). The anti-A titer in the recipient was 0 through Day 6, 4 on Day 7, and 128 on Day 8. Consequently, therewas no agglutination of group ARBCs in the presence of the patient's serum until after Day 6, when there was weak agglutination on Day 7 and 2+agglutination from Day 8 on. The patient was treated with RBC transfusions, corticosteroids, and four sessions of plasmapheresis. This allowed the hemolysis to resolve rapidly after all the patient's group A RBCs had been destroyed.

In the same period (i.e., Day 6-12), the patient developed acute GVHD, which attained an overall maximum grade of IV on Day 12, including gradellI skin GVHD, grade IV hepatic GVHD, and grade IV gastrointestinal GVHD, the latter of which was responsible for massive uncontrollable bleeding that compromised survival. Aggressivetherapy in-
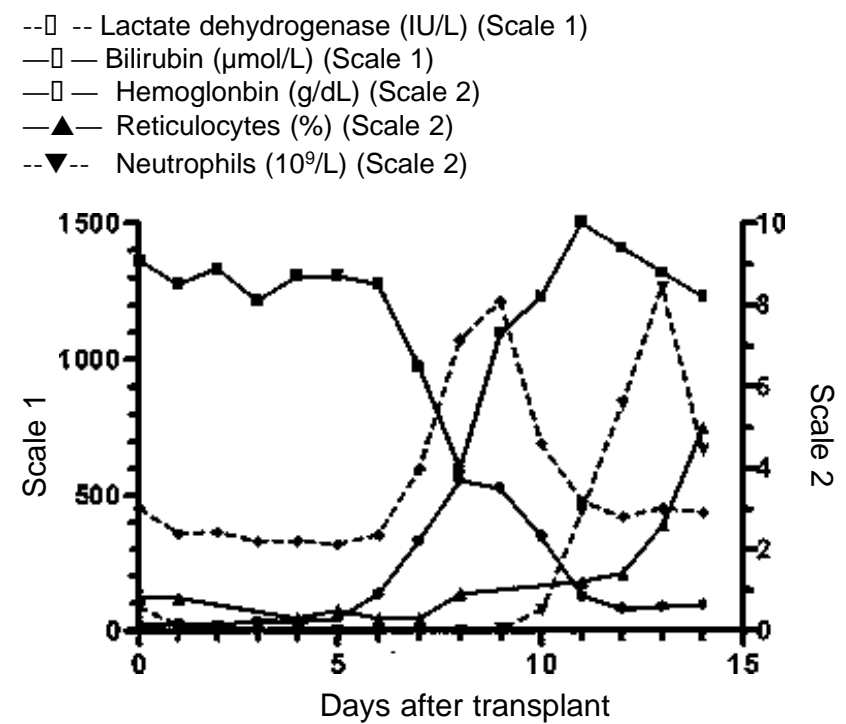

Fig. 1. Evolution of hematologic and hemolytic measures in the patient between Day 0 and Day 14 after transplant. 


\begin{tabular}{|c|c|c|c|}
\hline Day & $\begin{array}{c}\text { Patient's serum } \\
\text { and } A_{1} \text { RBCs }\end{array}$ & Anti-A titer & $\begin{array}{c}\text { ABO } \\
\text { phenotype }\end{array}$ \\
\hline 0 & Negative & Negative & A \\
\hline 1 & Negative & Negative & A \\
\hline 2 & Negative & Negative & A \\
\hline 4 & Negative & Negative & A \\
\hline 6 & Negative & Negative & A \\
\hline 7 & $(+)^{*}$ & 4 & $\dagger$ \\
\hline 8 & $++\ddagger$ & 128 & $\mathrm{O}$ \\
\hline \multicolumn{4}{|c|}{$\begin{array}{l}\text { Weakly positive. } \\
\text { Tixed-field population with very few group A RBCs in group } \\
\text { RBCs. } \\
\text { † } 2+\text { agglutination. }\end{array}$} \\
\hline
\end{tabular}

cluding cyclosporine A, corticosteroids, M24 monoclonal antibodies, methotrexate, and anti-thymocyte globulin proved unable to improve GVHD. On Day 24, a pulmonary infection of undetermined origin developed, causing the general condition to deterioratefurther. Death followed on Day 35, caused by liver failure and massivegastrointestinal bleeding secondary to acute GVHD.

\section{DISCUSSION}

The presence in the recipient of $\mathrm{ABO}$ antibodies against the $\mathrm{RBC}$ antigens of the donor is referred to as major $\mathrm{ABO}$ incompatibility. (This was not the case in our patient.) Apart from the risk of acute hemolysis at the time of transplant, there is also the fear that, if progenitor cells express ABO antigens, there could bean additional risk of graft rejection. However, this type of incompatibility does not engender GVHD or prejudice the prognosis for survival. ${ }^{1,2}$ In fact, rather than rejection of the graft, it seems to cause a prolonged RBC aplasia. To prevent complications, it is necessary to process the bone marrow ex vivo to eliminate the RBCs from the graft and in rare cases to carry out pretransplant plasma exchanges in the recipient. ${ }^{1-4}$ In most recipients, the antibodies disappear within 2 to 3 months, but, in those who present with high levels beforetransplant, there may be a rapid delayed increase in their titer with consecutive RBC aplasia.

Minor ABO incompatibility can bedefined by the presence in the donor of $A B O$ antibodies directed against the recipient's RBCs, as observed in our patient. This occurs in approximately 30 percent of marrow transplants and may be somewhat more frequent in the unrelated-donor setting. ${ }^{5}$ This situation is of concern only when the plasma antibody titer of the donor is such that it is likely to induce in the patient a hemolytic reaction during the return of the marrow, [which in the latter case the plasma] should beremoved. ${ }^{2}$ Allogeneic bone marrow transplantation carried out under these conditions can in general be performed without any acute problem. In principle, there is no effect on marrow recovery, no apparent increase in GVHD, and no consequence for the survival of the recipient. However, it appears that a moderate, delayed hemolytic reaction may occur 9 to 16 days after bone marrow transplantation in 10 to 30 percent of the cases. ${ }^{5,6}$ Rarely, massive hemolysis has been reported. ${ }^{7}$ Theoretically, a PBPC graft could further increase this hemolytic risk, with regard to its lymphocyteenriched content, ${ }^{8}$ but there are no epidemiologic data available to support this.

The patient discussed here never received plasma, with the exception of a small volume at the time of the transplant, which did not produce any significant degree of hemolysis. The serum from the donor, in this case the mother, did not contain any HLA antibodies but did havea substantial anti-A titer (2048), probably induced by her multiple previous pregnancies. An anamnestic immune response may have favored the high titer of $A$ antibodies in the recipient, actively produced by thelymphocytes grafted from the donor. These events were associated with a very precocious marrow recovery and caused a massive destruction of the recipient's RBCS.

Our case is the sixth reported in the literature of hemolysis after allogeneic minor-incompatiblePBPC transplantation..$^{8-12}$ Most cases occurred in the context of the transplant of group A PBPCs to group O recipients (Table 2). Although it theoretically could further increase the risk of hemolysis, a high antibody titer in the donor does not appear to be required for this to happen. This episode, combined with very severe acute GVHD, precipitated the degradation of the general condition of the patient, leading to death. Whereas no HLA antibodies were detected in the mother, the patient developed very severe GVHD immediately after hematologic recovery, despite the classic use of cyclosporineA. CyclosporineA is capable of stimulating an exaggerated immune response that favors the proliferation of B-lymphocytes, combined with the suppression of the hel perT-lymphocytes, which allows for the development of hemolysis. ${ }^{5,6}$

Because of the very high risk of leukemia relapsein this patient, no intravenous methotrexate was given, in the hope of inducing a graft-versus-leukemia effect. The fact that no methotrexatehad been received may likewise have contributed to the development of the hemolytic reaction, inasmuch asthis medication istoxic to B-lymphocytes and may therefore prevent the production of the antibodies necessary for the occurrence of the passenger lymphocyte syndrome. ${ }^{5,8}$ Indeed, among PBPC cases, only one patient received 2 doses of methotrexate (Table 2), and GVHD prophylaxis incorporating methotrexate prevented the syndrome after marrow transplantation. ${ }^{5}$ The literature likewise makes reference to the fact that methotrexate may prevent hemolysis affecting transfused group O RBCs that is possibly mediated through absorption of $A$ or $B$ antigens on their surface. ${ }^{5} \mathrm{High}$ doses of intravenous immunoglobulins may also be associated with a brief episode of moder- 


\begin{tabular}{lcccccc}
\multicolumn{2}{l}{ TABLE 2. Clinical and laboratory data on patients with immune hemolysis after allogeneic minor ABO-incompatible } \\
PBPC transplantation
\end{tabular}

* $\mathrm{AML}=$ acute myeloblastic leukemia; $\mathrm{MM}=$ multiple myeloma; $\mathrm{ALL}=$ acute lymphoblastic leukemia; $\mathrm{CML}=$ chronic myelogenous leukemia ; $\mathrm{Cy}=$ cyclophosphamide; $\mathrm{Bu}=$ busulfan; $\mathrm{TBI}=$ total body irradiation; $\mathrm{MTX}=$ methotrexate; $\mathrm{mPDN}=$ methylprednisolone; $\mathrm{MOF}=$ multi-organ failure; $\mathrm{PMNs}=$ polymorphonuclear neutrophils $; \mathrm{LDH}=$ lactate dehydrogenase.

ate hemolysis immediately after their infusion. ${ }^{5}$ All these factorsmay have contributed to themassivehemolysisthat developed in our patient.

Our observation confirms the potential hemolytic risk of using a graft of PBPCs with a minor ABO incompatibility. ${ }^{8-12}$ Two additional considerations may haveaccentuated the phenomenon in our patient: 1 ) a gestational sensitization and 2) a high lymphocyte content in the graft. This type of hemolytic reaction could be minimized by the inclusion of methotrexate in the program of GVHD prophylaxis, as well as by the elimination of B-lymphocytes from the graft-for instance, through CD34 selection.

\section{REFERENCES}

1. Urbaniak SJ. Role of large volume exchange in bone marrow transplantation. Med Hyg 1985;43:1602-7.

2. Rodet M, Beaujean F, Duedari N. Transplantation of ABOincompatible bone marrow. Med Hyg 1985;43:1573-6.

3. Gmur JP, Burger J, Schaffner A, et al. Pure red cell aplasia of long duration complicating major $\mathrm{ABO}$-incompatible bone marrow transplantation. Blood 1990;75:290-5.

4. Braine HG, Sensenbrenner LL, Wright SK, et al. Bone marrow transplantation with major $\mathrm{ABO}$ blood group incompatibility using erythrocyte depletion of marrow prior to infusion. Blood 1982;60:420-5.

5. Gajewski JL, Petz LD, Calhoun L, et al. Hemolysis of transfused group O red blood cells in minor ABO-incompatible unrelated-donor bone marrow transplantation in patients receiving cyclosporine without posttransplant methotrexate. Blood 1992;79:3076-85.

6. Hows J, Beddow K, Gordon-Smith E, et al. Donor-derived red blood cell antibodies and immune hemolysis after allogeneic bone marrow transplantation. Blood 1986;67:177-81.

7. Greeno EW, Perry EH, Ilstrup SJ, Weisdorf DJ. Exchange transfusion the hard way: massive hemolysis following transplantation of bone marrow with minor ABO-incompatibility. Transfusion 1996;36:71-4.

8. Toren A, Dacosta Y, Manny N, et al. Passenger B-lymphocyte-induced severe hemolytic disease after allogeneic peripheral blood stem cell transplantation (letter). Blood 1996;87:843-4.

9. Laurencet FM, Samii K, Bressoud A, et al. Massive delayed hemolysis following peripheral blood stem cell transplantation with minor ABO incompatibility. Hematol Cell Ther 1997;39:159-62.

10. Oziel-Taieb S, Faucher-Barbey C, Chabannon C, et al. Early and fatal immune haemolysis after so-called 'minor' ABOincompatible peripheral blood stem cell allotransplantation. Bone Marrow Transplant 1997;19:1155-6.

11. Moog R, Melder C, Prumbaum M, et al. Rapid donor type isoagglutinin production after allogeneic peripheral progenitor cell transplantation. Beitr Infusionsther Transfusionsmed 1997;34:150-2.

12. Bornhauser $M$, Ordemann $R, P a a z U$, et al. Rapid engraftment after allogeneic ABO-incompatible peripheral blood progenitor cell transplantation complicated by severe hemolysis. Bone Marrow Transplant 1997;19:295-7. [ 